Please do not remove this page

RMIT

UNIVERSITY

\title{
Nanostructured SnO2 films prepared from evaporated Sn and their application as gas sensors
}

Partridge, James; Field, Matthew; Peng, J; Sadek, Abu Zafar Md; Kalantar Zadeh, Kourosh; Du Plessis, Johan; McCulloch, Dougal

https://researchrepository.rmit.edu.au/esploro/outputs/9921863114701341/filesAndLinks?institution=61RMIT_INST\&index=null

Partridge, J., Field, M., Peng, J., Sadek, A. Z. M., Kalantar Zadeh, K., Du Plessis, J., \& McCulloch, D. (2008). Nanostructured $\mathrm{SnO} 2$ films prepared from evaporated $\mathrm{Sn}$ and their application as gas sensors.

Nanotechnology, 19(12), 1-5. https://doi.org/10.1088/0957-4484/19/12/125504

Document Version: Accepted Manuscript

Published Version: https://doi.org/10.1088/0957-4484/19/12/125504

Repository homepage: https://researchrepository.rmit.edu.au

(C) Institute of Physics and IOP Publishing Limited 2009

Downloaded On 2023/04/26 09:51:39 +1000 


\title{
Nanostructured $\mathrm{SnO}_{2}$ films prepared from evaporated $\mathrm{Sn}$ and their
}

\section{application as gas sensors}

\author{
J G Partridge ${ }^{1}$, M R Field ${ }^{1}$, J L Peng ${ }^{1}$, A Z Sadek ${ }^{2}$, K Kalantar-zadeh ${ }^{2}$, J Du Plessis ${ }^{1}$ \\ and D G McCulloch ${ }^{1,3}$ \\ ${ }^{1}$ Applied Physics, School of Applied Sciences, RMIT University, Melbourne, Victoria \\ 3001, Australia \\ ${ }^{2}$ School of Electrical and Computer Engineering, RMIT University, Melbourne, Victoria \\ 3001, Australia \\ ${ }^{3}$ Email: dougal.mcculloch@rmit.edu.au
}

\begin{abstract}
This paper describes the morphology, stoichiometry, microstructure and gas sensing properties of nano clustered $\mathrm{SnO}_{\mathrm{x}}$ thin films prepared by $\mathrm{Sn}$ evaporation followed by the Rheotaxial Growth and Thermal Oxidation (RGTO) process. Electron microscopy was used to investigate, in detail, the evolution of the films as the oxidation temperature was increased. The results showed that the contact angle, perpendicular height, volume and microstructure of the clusters all changed significantly as a result of the thermal oxidation processes. Electron diffraction and X-ray photoelectron spectroscopy measurements revealed that after oxidation at a temperature of $600{ }^{\circ} \mathrm{C}$, the $\mathrm{Sn}$ clusters were fully transformed into porous 3-dimensional polycrystalline $\mathrm{SnO}_{2}$ clusters. Based on these results, a prototype $\mathrm{SnO}_{2}$ sensor was fabricated and sensing measurements were performed with $\mathrm{H}_{2}$ and $\mathrm{NO}_{2}$ gases. At operating temperatures of $150{ }^{\circ} \mathrm{C}-200{ }^{\circ} \mathrm{C}$ the film produced measurable responses to concentrations of $\mathrm{H}_{2}$ as low as $600 \mathrm{ppm}$ and $\mathrm{NO}_{2}$ as low as 500 ppb.
\end{abstract}


PACS CODES: 07.07.Df (Sensors), 36.40.-c (Atomic and molecular clusters), 81.07.-b (Nanoscale materials and structures: fabrication and characterization). 


\section{Introduction}

$\mathrm{SnO}_{2}$ is a semiconducting metal oxide which has received a great deal of attention from researchers and industry alike. This is largely due to its gas sensing capability (see for example [1]). Nano-structured $\mathrm{SnO}_{2}$ films have been produced by various research groups as their surface to volume ratio is large and they offer potentially higher sensitivity as a result (see for example $[2,3,4]$ ). With careful process control, the size of the grains within the films can be made comparable to the depth of the space-charge layer formed within each grain, thereby further improving sensitivity. However, the relationship between the electrical and nano-structural properties of sensing films has not yet been fully established [3].

The list of applications for $\mathrm{SnO}_{2}$ does not end with sensors. Undoped and doped transparent conducting $\mathrm{SnO}_{2}$ films have been studied extensively because they can exhibit high optical transmission and electrical conduction [5]. Recently, lightly Ta-doped $\mathrm{SnO}_{2}$ nanowires were also used to produce fully transparent FET type devices [6]. The increasing number of applications for this material provides further motivation for investigating the structure of films, clusters and nanowires and relating the findings to electrical, optical and mechanical properties.

Deposition methods employed to produce $\mathrm{SnO}_{2}$ films include pulsed laser deposition [7], evaporation [8] and sputtering [9]. $\mathrm{SnO}_{2}$ films can also be readily produced from $\mathrm{Sn}$ films followed by thermal oxidation. The latter approach is potentially useful for gas sensing applications because $\mathrm{Sn}$ films tend to grow on oxide surfaces in the Volmer Weber mode (ie. as islands or clusters) and with high area-to-volume ratios. The rheotaxial growth and thermal oxidation (RGTO) process was developed with the aim of retaining the morphology of the original $\mathrm{Sn}$ film after conversion to $\mathrm{SnO}_{2}[10]$. Stage one of the process involves heating the Sn sample (in the presence of oxygen) to a temperature just below the melting point of Sn (typically about $200{ }^{\circ} \mathrm{C}$ ) in order to increase the thickness of the native oxide layer. This thickened oxide shell 
supports the Sn core and resists deformation during a subsequent higher temperature process (typically 600 ${ }^{\circ} \mathrm{C}-700{ }^{\circ} \mathrm{C}$ ) which transforms the remaining $\mathrm{Sn}$ into $\mathrm{SnO}_{2}$. The $\mathrm{RGTO}$ method has been used by various research groups and has proved effective for complete oxidation of films, and nanowires $[8,11]$. Despite its widespread use, a detailed microstructural investigation of the evolution of $\mathrm{Sn}$ films into $\mathrm{SnO}_{2}$ using the RGTO process has not yet been performed.

Previous studies on $\mathrm{SnO}_{2}$ thin films produced by thermal oxidation of $\mathrm{Sn}$ thin films have been reported $[12,13,14]$ and these papers have described the phase transformations which occur during thermal oxidation at various temperatures. However, despite their suitability for sensing applications, a detailed Transmission Electron Microscopy (TEM) study of the nanostructure of thermally oxidised $\mathrm{SnO}_{2}$ cluster/island films is absent from the literature. In this paper, we employ X-ray photoelectron spectroscopy and electron microscopy to investigate the stoichiometry, microstructure and morphology of evaporated Sn cluster films following RGTO processing to different maximum temperatures. Plane view and cross-sectional TEM have been used to provide a detailed view of the microstructure of thermally oxidised $\mathrm{SnO}_{2}$ films. Finally, based on these results, a prototype RGTO processed $\mathrm{SnO}_{2}$ sensor was fabricated and its sensitivity to $\mathrm{NO}_{2}$ and $\mathrm{H}_{2}$ was investigated.

\section{Experiment}

\subsection{Sample preparation}

P-type $\mathrm{Si}$ substrates with a $1 \mu \mathrm{m}$ thickness layer of $\mathrm{SiO}_{2}$ were selected to support the $\mathrm{Sn}$ and $\mathrm{SnO}_{\mathrm{x}}$ films. Four samples were prepared in a single deposition process. Sn (99.99\% purity pellet) was thermally evaporated from a tungsten filament boat inside a DynaVac coating system to produce a film with a nominal deposited thickness of $40 \mathrm{~nm}$ on each of the four $\mathrm{SiO}_{2}$ covered $\mathrm{Si}$ substrates. The deposition rate was approximately $0.2 \mathrm{~nm} / \mathrm{s}$ and the base pressure and process pressure were $1 \times 10^{-6}$ Torr and $5 \times 10^{-6}$ 
Torr, respectively. After the deposition, these samples were processed individually as follows; Sample 'AsDep' was the as-deposited sample, sample 'Ox200' was heated to $200^{\circ} \mathrm{C}$, sample 'Ox400' was heated to $200{ }^{\circ} \mathrm{C}$ then $400{ }^{\circ} \mathrm{C}$ and sample 'Ox600' was heated to $200{ }^{\circ} \mathrm{C}, 400{ }^{\circ} \mathrm{C}$ and finally $600{ }^{\circ} \mathrm{C}$. Samples were held at each temperature $\left(200{ }^{\circ} \mathrm{C}, 400{ }^{\circ} \mathrm{C}\right.$ and $\left.600{ }^{\circ} \mathrm{C}\right)$ for 2-hours and the ramp time between these temperatures was approximately 30 minutes. The samples were all heated in air at atmospheric pressure using a simple bench-top furnace. Samples with coverage approximately equal to the percolation threshold were prepared so that individual clusters could be counted and measured reliably from Scanning Electron Microscopy (SEM) images. Adopting this coverage also enabled images of individual cross-sectioned clusters to be produced by TEM.

The contacted substrate required for the gas sensing measurements was fabricated using a photo-plot mask and optical lithography. The total length of each interdigital-type contact was approximately $35 \mathrm{~mm}$ and the contact-to-contact separation was approximately $100 \mu \mathrm{m}$. A prototype sensor with a $\mathrm{SnO}_{2}$ film of $80 \%$ area coverage (ie. just above the percolation threshold) was produced initially but its resistance was too high for reliable sensing measurements. An evaporation-RGTO-evaporation-RGTO process sequence was then used to produce a device with a thicker porous $\mathrm{SnO}_{2}$ film. This had a resistance at $200{ }^{\circ} \mathrm{C}$ in air of approximately $8 \mathrm{k} \Omega$. Alternating evaporations and RGTO processes have previously been employed to produce 'stacked' $\mathrm{SnO}_{2}$ cluster films with high surface area and reduced film resistance [15]. A nominal thickness of $40 \mathrm{~nm}$ was deposited in each of the two evaporations and the temperature sequence for the thermal oxidation was identical to that used for the $O x 600$ sample; $200{ }^{\circ} \mathrm{C}$ (2-hrs), then $400{ }^{\circ} \mathrm{C}$ (2-hrs) and finally $600{ }^{\circ} \mathrm{C}$ (2-hrs) with 30-min ramp times between each set-point temperature. Once complete, the sample was placed in a multi-channel gas calibration system and the contact-to-contact resistance was measured during timed exposures to various concentrations of $\mathrm{NO}_{2}$ gas.

\subsection{Electron Microscopy and X-ray Photoelectron Spectroscopy}


SEM imaging of the samples was performed using a FEI-Nova NanoSEM and image processing software enabled particle counts and particle areas to be calculated from the captured images. TEM specimens were prepared either in plane view or cross-section by mechanical polishing using a tripod polisher, followed by Ar ion beam thinning to electron transparency. They were analysed in a JEOL 2010 Transmission Electron Microscope operating at $200 \mathrm{kV}$.

X-ray Photoelectron Spectroscopy (XPS) was performed on a VG Microlab 310F with a dual Al/Mg anode unmonochromated X-ray source operated at a power of $300 \mathrm{~W}$ and with a $15 \mathrm{kV}$ excitation voltage. The sample was tilted such that the electron analyzer normal to the sample surface collected the escaping electrons. The analyzed area is determined by the electrostatic lens and slits of the analyzer and in this case the rectangular area was approximately $5 \times 1 \mathrm{~mm}^{2} . \mathrm{A} \mathrm{SnO}_{2}$ powder standard [16] was used to calibrate the sensitivity factors prior to the measurements and the samples were sputtered in-situ with Ar gas (at a pressure of $0.2 \mu$ Torr) in order to purge the surface of carbon contaminants.

\section{Results and Discussion}

\section{1. $\mathrm{SnO}_{2}$ cluster film morphology and area distribution}

Figure 1 shows the surface morphology of the evaporated $\mathrm{Sn} / \mathrm{SnO}_{\mathrm{x}}$ films. Fig. 1(a) shows sample AsDep (with no RGTO treatment) whilst Fig. 1(b) shows the $O x 400$ sample and Fig. 1(c) shows the Ox600 sample. The corresponding area distributions obtained from the images in Fig. 1 are shown in Fig. 2. The as-deposited film has grown in Volmer-Weber mode and consists of islands (clusters) with an average area of $4000 \mathrm{~nm}^{2}$. In addition to large islands, there is a population of small islands with areas of less than 2000 $\mathrm{nm}^{2}$. It can be seen from Fig. 2 that following oxidation at $600{ }^{\circ} \mathrm{C}$, there is a tendency for the average island area to increase (from $4000 \mathrm{~nm}^{2}$ to $5500 \mathrm{~nm}^{2}$ ). This increase in the area of the islands can be attributed to coalescence of neighbouring islands and Ostwald ripening [17]. The population of small islands that 
remained following annealing suggested that these islands were less mobile and therefore less able to coalesce with their neighbours.

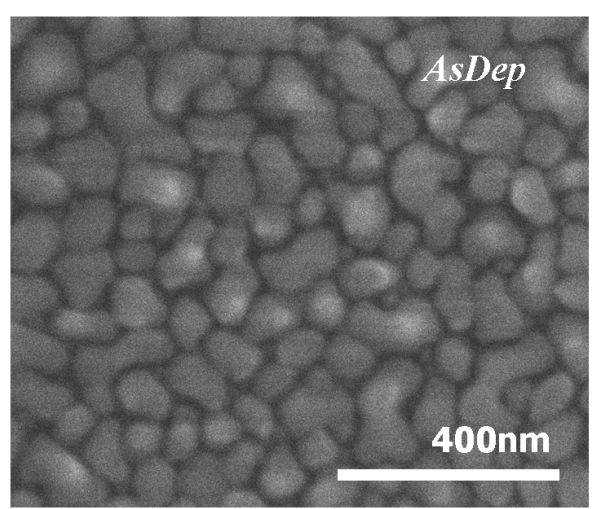

(a)

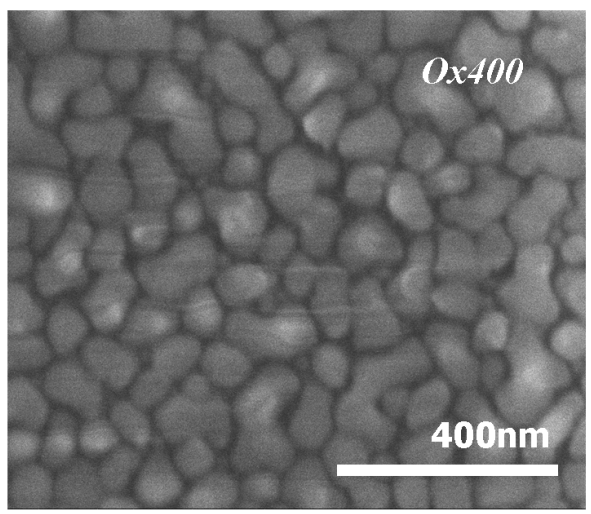

(b)

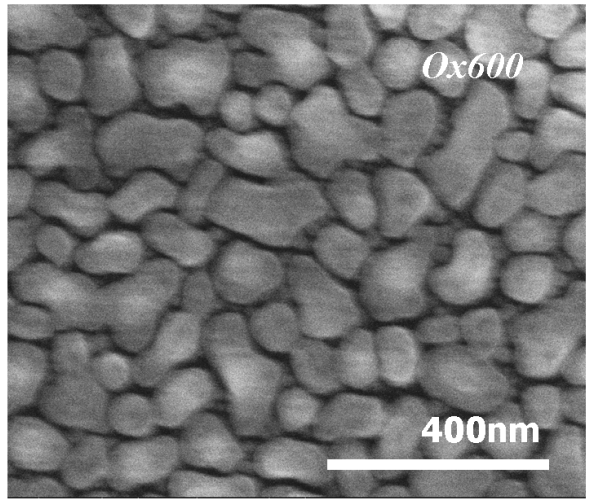

(c)

Figure 1. SEM images of evaporated Sn cluster films (a) as deposited, (b) after oxidation at temperatures of $200{ }^{\circ} \mathrm{C}$ and $400{ }^{\circ} \mathrm{C}$ and (c) after oxidation at temperatures of $200{ }^{\circ} \mathrm{C}, 400{ }^{\circ} \mathrm{C}$ and $600{ }^{\circ} \mathrm{C}$. 


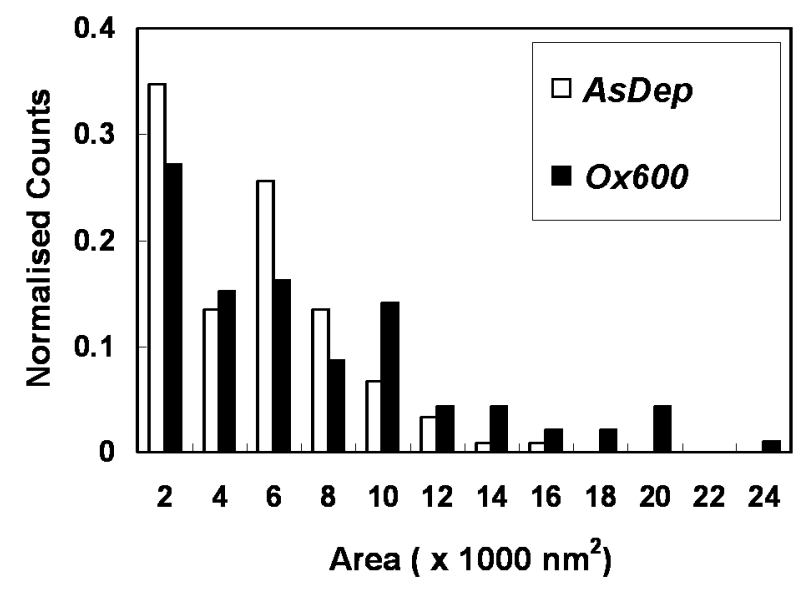

Figure 2. Cluster area distributions within thermally evaporated $\mathrm{Sn}$ films as deposited (sample-AsDep) and after oxidation at temperatures of $200{ }^{\circ} \mathrm{C}, 400{ }^{\circ} \mathrm{C}$ and $600{ }^{\circ} \mathrm{C}$ (sample-Ox600).

\subsection{XPS measurement of stoichiometry}

X-ray Photoelectron Spectroscopy (XPS) spectra in the vicinity of the Sn 3d peaks from the asdeposited and $O x 600$ samples are shown in Fig. 3. The Sn $3 \mathrm{~d} 5$ spectrum from the as-deposited sample has a main peak at approximately $487 \mathrm{eV}$ which corresponds to a mixture of predominantly $\mathrm{SnO}_{2}$ and other oxidation states as well as a shoulder at approximately $485 \mathrm{eV}$ which corresponds to metallic Sn [18]. This indicates that the islands on the as-deposited film are partially oxidised. Following annealing only peaks from $\mathrm{SnO}_{2}$ are observed [18] and this stoichiometry was confirmed using peak area analysis. It is important to note that XPS can only probe the near surface region of a sample so the composition of the various samples was also investigated using selected area diffraction analysis (see below). 


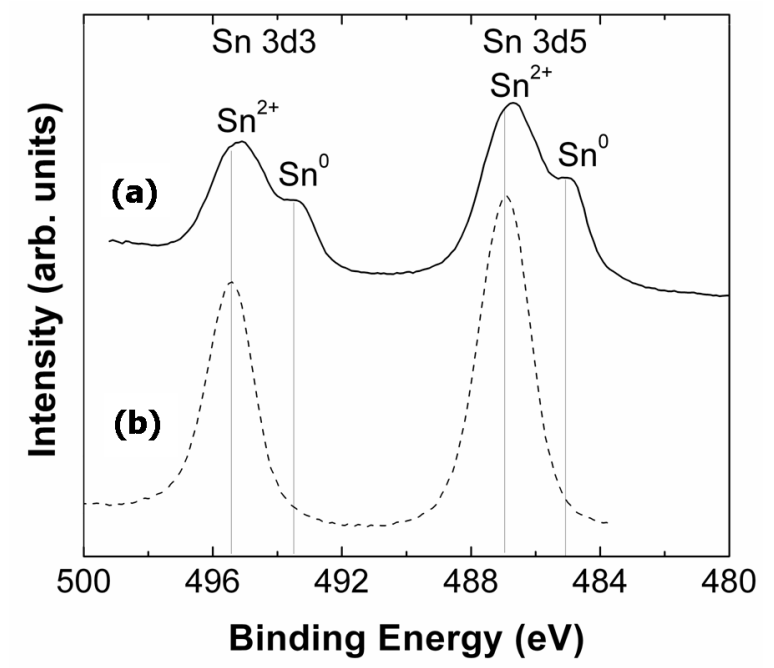

Figure 3. XPS spectra for evaporated Sn (a) as-deposited and (b) after oxidation at temperatures of $200^{\circ} \mathrm{C}$, $400{ }^{\circ} \mathrm{C}$ and $600^{\circ} \mathrm{C}$.

\subsection{TEM characterization of $\mathrm{SnO}_{2}$ cluster films}

Plan view TEM images of the as-deposited and the sample $O x 600$ are shown in Fig. 4. The AsDep sample (Fig. 4(a)) contained irregular shaped islands from $5 \mathrm{~nm}$ to $100 \mathrm{~nm}$ in length and with heights less than $30 \mathrm{~nm}$. A thin surface oxide shell (approximately $3 \mathrm{~nm}$ in thickness) can also be seen surrounding the islands. This oxide layer is expected to have grown after the samples were removed from the deposition system. Following oxidation at $600{ }^{\circ} \mathrm{C}$, the discrete cores and oxide shells were no longer visible and the microstructure of the $\mathrm{SnO}_{x}$ clusters became more complex, containing small crystallites and voids. Selected area diffraction patterns from the as-deposited and $0 x 600$ sample (not shown) could be indexed to metallic $\mathrm{Sn}$ and rutile $\mathrm{SnO}_{2}$, respectively. No evidence could be found for metallic $\mathrm{Sn}$ reflections in the diffraction pattern from the $0 x 600$ sample indicating that the Sn clusters had fully transformed into $\mathrm{SnO}_{2}$ following oxidation to $600{ }^{\circ} \mathrm{C}$. 


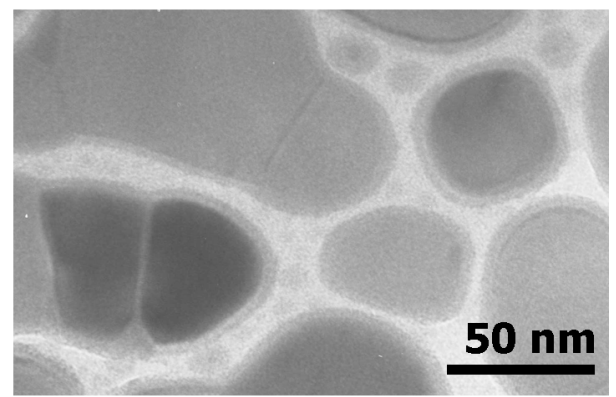

(a)

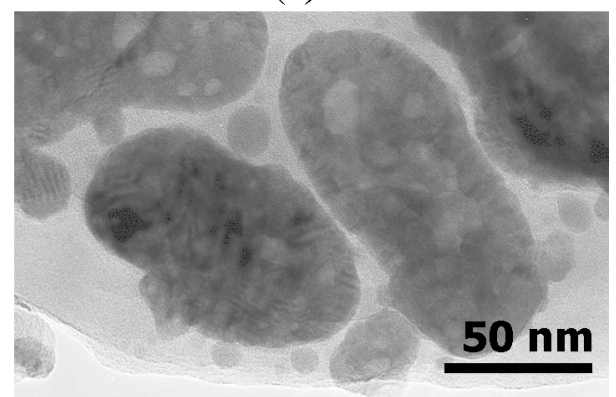

(b)

Figure 4. Plan view TEM images of evaporated Sn clusters (a) as-deposited and (b) after oxidation at temperatures of $200{ }^{\circ} \mathrm{C}, 400{ }^{\circ} \mathrm{C}$ and $600^{\circ} \mathrm{C}$.

The changes in morphology and structure of the islands which occur due to the annealing process are seen in more detail in the cross-sectional TEM (X-TEM) images shown in Fig. 5. The discrete core and shell structure of the as-deposited islands (Fig. 5(a) - sample AsDep) was again clearly evident, and grew thicker (from $\sim 3 \mathrm{~nm}$ to $\sim 8 \mathrm{~nm}$ ) after oxidation at $200{ }^{\circ} \mathrm{C}$ (Fig. 5(b) - sample $O x 200$ ). A thin $\mathrm{SnO}_{\mathrm{x}}$ layer can also be seen at the island-surface interface which is believed to have formed due to the presence of water vapour on the sample surface during the thermal evaporation process. Using additional X-TEM images of the islands on the $O x 200$ sample, it was found that in smaller islands (with lengths less than 20 $\mathrm{nm}$ ) the oxide shells always occupied more than $50 \%$ of the island's cross-sectional area. Once oxidised, these islands become less mobile and less able to coalesce, which explains the population of small islands (with areas less than $2000 \mathrm{~nm}^{2}$ ) observed on samples $O x 400$ and $O x 600$. X-TEM images of the samples $O x 400$ and $O x 600$ are shown in Figs. 5(c) and 5(d), respectively. The Sn cores are no longer visible and the 
perpendicular height to length ratio has clearly changed as a result of the higher temperatures experienced by these samples. The $0 x 600$ sample was obviously polycrystalline and the crystallites in the crosssectioned $O x 600$ clusters had areas of between $5 \mathrm{~nm}^{2}$ and $500 \mathrm{~nm}^{2}$.

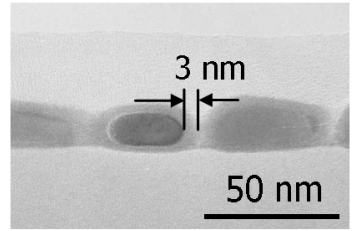

(a)

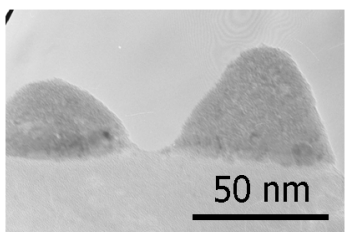

(c)

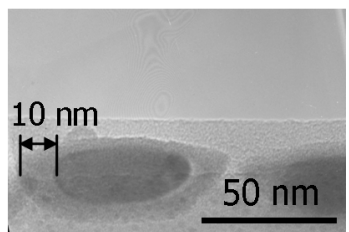

(b)

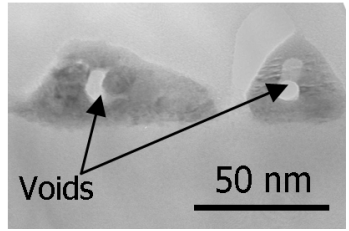

(d)

Figure 5. $\mathrm{X}$-TEM images of $\mathrm{Sn} / \mathrm{SnO}_{\mathrm{x}} / \mathrm{SnO}_{2}$ clusters (a) as-deposited, (b) after oxidation at $200{ }^{\circ} \mathrm{C}$, (c) after oxidation at temperatures of $200{ }^{\circ} \mathrm{C}$ and $400{ }^{\circ} \mathrm{C}$ and (d) after oxidation at temperatures of $200{ }^{\circ} \mathrm{C}, 400{ }^{\circ} \mathrm{C}$ and $600{ }^{\circ} \mathrm{C}$.

The contact angle for the as-deposited Sn islands is typically greater than $120^{\circ}$. The islands therefore exhibit a low thermodynamic work of adhesion $\left(W_{a d}<0.4 \mathrm{~J} \mathrm{~m}^{-2}\right)$ according to the Young-Dupre equation [19],

$$
W_{a d}=\gamma_{m}(1+\cos \theta)
$$

where $\gamma_{m}$ is the surface energy of the metal, $\theta$ is the contact angle and $W_{a d}$ is the work of adhesion. This is consistent with the expected wetting behaviour for low melting point metal islands supported on a metal or silicon oxide. Following annealing, the contact angle of the oxidised islands becomes sub- $90^{\circ}$ as they change into a mould like shape. This change in morphology can be attributed to two competing mechanisms. Firstly, the island is 'anchored' to the substrate due to the strength of the bond between the interfacial oxide and the underlying $\mathrm{SiO}_{2}$. Secondly, as the temperature exceeds $230{ }^{\circ} \mathrm{C}$ and the $\mathrm{Sn}$ core 
becomes molten, it adopts an energetically favourable sphere-like shape. The surface oxide conforms to the sphere-like core except at the island-substrate interface where it remains firmly adhered as the energy of attachment is high for an oxide-oxide interface. The contact angle of the island therefore reduces as a result of the oxidation process. As the perpendicular height of the fully oxidised islands is significantly greater than that of the as-deposited islands, the volume of the islands has increased. The average volumetric change was estimated from the TEM and SEM images to be more than $50 \%$. Thermally assisted coalescence of neighbouring clusters and the formation of pores, which were clearly visible in the clusters of the $0 x 600$ sample, were responsible for the larger than expected volume increase. One explanation for the occurrence of these voids may be that if the temperature exceeds $400{ }^{\circ} \mathrm{C}$, any remaining Sn out-gasses sufficiently to create 'bubbles' which cannot escape through the surrounding oxide. Alternatively, they may be caused simply by thermal expansion and contraction of $\mathrm{Sn}$ and/or $\mathrm{SnO}_{\mathrm{x}}$ within the clusters occurring as a result of the RGTO process. Some densification of the $\mathrm{SnO}_{2}$ is expected to occur due to crystallisation at temperatures between $400{ }^{\circ} \mathrm{C}$ and $600{ }^{\circ} \mathrm{C}$ but it is unlikely that this effect alone is capable of producing voids as large as those seen in the $0 x 600$ sample.

\subsection{Gas sensing measurements}

The attributes of the $\mathrm{SnO}_{2}$ film which was oxidised at temperatures up to $600{ }^{\circ} \mathrm{C}$ (high surface-area, nanoscale clusters and pores) suggested that it may be capable of gas sensing. A prototype sensor was therefore fabricated and tested. Fig. 6(a) shows a SEM image of a $\mathrm{RGTO}$ treated $\mathrm{SnO}_{2}$ cluster film supported on dual inter-digital eletrodes and a passivated Si substrate. As mentioned previously, this film was produced using two evaporations with RGTO processes following each of the evaporations. TEM inspection of a small section of the film revealed that the clusters were polycrystalline with similar nanostructure to that shown in Fig. 5(d). The sensor film clearly has high surface area and appears corallike in its morphology (as seen in Fig. 6(a)). Neighbouring clusters are more densely packed in this thicker film than they are in the films shown in Fig. 1 and the probability of coalescence is therefore higher. 


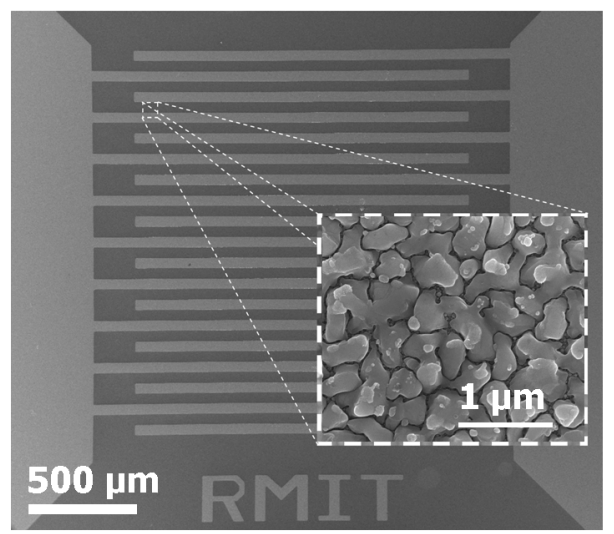

(a)

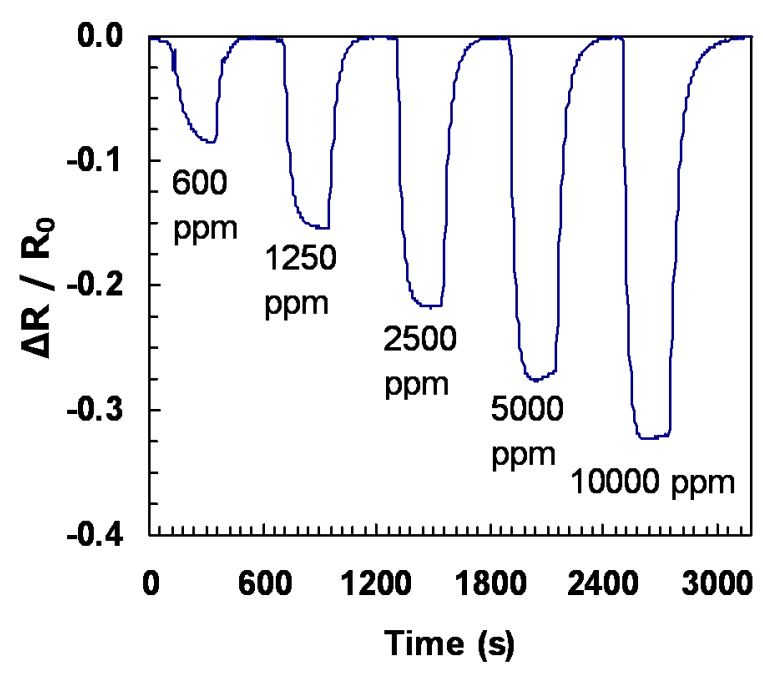

(b)

Figure 6. (a) $\mathrm{A} \mathrm{SnO}_{2}$ thin-film deposited on $\mathrm{Au}$ interdigital electrodes and (b) the normalised resistance change exhibited by the film when exposed to different concentrations of hydrogen gas (as marked in ppm) and operating at a temperature of $150^{\circ} \mathrm{C}$.

Fig. 6(b) shows the normalised change in resistance $\left(\Delta R / R_{0}\right.$, where $R_{0}$ is the resistance with zero exposure) caused by pulsed hydrogen exposures of concentrations 625 ppm, 1250 ppm, 2500 ppm, 5000 ppm and $10000 \mathrm{ppm}$ at a temperature of $150{ }^{\circ} \mathrm{C}$. With a $\mathrm{H}_{2}$ gas concentration of $2500 \mathrm{ppm}$, the response and recovery times for the sensor were $50 \mathrm{~s}$ and $70 \mathrm{~s}$, respectively. $\mathrm{NO}_{2}$ gas sensing tests were also performed and upon exposure to a concentration of $\mathrm{NO}_{2}$ gas of $500 \mathrm{ppb}$, the resistance of the film increased from 
$8.4 \mathrm{k} \Omega$ to $18.9 \mathrm{k} \Omega$. The response and recovery times exhibited for this concentration of $\mathrm{NO}_{2}$ were $50 \mathrm{~s}$ and $90 \mathrm{~s}$, respectively. These results compare favourably with previous results for undoped $\mathrm{SnO}_{2}$ thin-film sensors [4]. We are now planning to use the prototype sensor and TEM to assess whether the structure of the porous polycrystalline $\mathrm{SnO}_{2}$ film remains stable after long term exposure to $\mathrm{NO}_{2}$ and $\mathrm{H}_{2}$.

\section{Summary}

The RGTO technique was used to prepare $\mathrm{SnO}_{\mathrm{x}}$ clusters from discontinuous evaporated Sn thin films. Samples with different ultimate oxidation temperatures were characterised and the stoichiometry, morphology and micro-structure determined. Selected area diffraction patterns and TEM images showed that the as-deposited Sn clusters were polycrystalline with a $\sim 3 \mathrm{~nm}$ thick native oxide layer and a well defined inner Sn core. The remaining samples showed that the oxide layer grows to $\sim 8 \mathrm{~nm}$ thickness after oxidation for 2-hrs at $200{ }^{\circ} \mathrm{C}$ and the metallic Sn core was no longer evident when the maximum oxidation temperature was $400{ }^{\circ} \mathrm{C}$ or $600{ }^{\circ} \mathrm{C}$. XPS and selected area diffraction showed that the clusters oxidised up to $600{ }^{\circ} \mathrm{C}$ were substantially $\mathrm{SnO}_{2}$, as previously reported and that they were polycrystalline. Crystallites with cross-sectional areas of between $5 \mathrm{~nm}^{2}$ and $500 \mathrm{~nm}^{2}$ were seen in these clusters. Whilst the morphology of the $\mathrm{SnO}_{2}$ cluster film was not dramatically different from the as-deposited $\mathrm{Sn}$ cluster film, the average volume of the $\mathrm{SnO}_{2}$ clusters was significantly larger. Voids were found in many of the $\mathrm{SnO}_{2}$ clusters and undoubtedly contributed to the observed increase in volume. Finally, a prototype sensor based on RGTO processed thermally evaporated Sn was tested and found to exhibit good sensitivity to $\mathrm{H}_{2}$ and $\mathrm{NO}_{2}$ gases making them suitable for many commercial applications. 


\section{REFERENCES}

[1] Ihokura K and Watson J 1994 The Stannic Oxide Gas Sensor: Principles and Applications (Florida: CRC Press)

[2] Schierbaum K D, Weimar U and Goepel W 1992 Sensors and Actuators B 7709

[3] Kalantar-zadeh K and Fry B 2007 Nanotechnology-Enabled Sensors (New York: Springer)

[4] Lou X, Peng C, Wang X and Chu W 2007 Vacuum 81883

[5] Shanthi E, Dutta V, Banerjee A and Chopra K L 1980 J. Appl. Phys. 516243

[6] Dattoli E N, Wan Q, Guo W, Chen Y, Pan X and Lu W 2007 Nano Letters 72463

[7] El Khakani M A, Dolbec R, Serventi A M, Horrillo M C, Trudeau M, Saint-Jacques R G, Rickerby D G and Sayago I 2001 Sensors and Actuators B 77383

[8] Pan X Q and Fu L 2001 Journal Applied Physics 896048

[9] Micocci G, Tepore A, Serra A, Siciliano P and Ali-Adib Z 1996 Vacuum 471175

[10] G Sberveglieri G, G Faglia G, S Groppelli S, P Nelli P and Camanzi A 1990 Semiconductor Science and Technology 51231

[11] Kolmakov A, Zhang Y and Moskovits M 2003 Nano Letters 31125

[12] Geurts J, Rau S, Richter W and Schmitte F J 1984 Thin Solid Films 121217

[13] Park G-S and Yang G-M 2000 Thin Solid Films 3657

[14] Nelli P, Faglia G, Sberveglieria G, Ceredab E, Gabettab G, Dieguezc A, Romano-Rodriguezc A and Morante J R 2000 Thin Solid Films 371249

[15] Aste T, Botter R and Beruto D 1995 Sensors and Actuators B 24826

[16] Sigma Aldrich SnO2 Prod. no. 244651-100G 99.9\% -325 mesh

[17] Ostwald W 1900 Z. Phys. Chem. 34495

[18] Briggs D and Seah M P (Ed.) 1990 Practical Surface Analysis $2^{\text {nd }}$ edition Vol. 1 Auger and Xray Photoelectron Spectroscopy (England: Wiley) p. 642

[19] Howe J M 1997 Interfaces in Materials (New York: Wiley) p. 182 